\title{
STUDY ON STRUCTURE AND CRYSTALLIZATION OF POLYPROPYLENE GRAFTED MALEIC ANHYDRIDE/NANOCLAY COMPOSITE
}

\author{
Bui Chuong* and Dang Viet Hung \\ Polyme Centre, Hanoi University of Technology, \\ 01 Dai Co Viet Rd., Hanoi, Vietnam
}

Received 09 August 2006

\begin{abstract}
Nanocomposite from polypropylene grafted maleic anhydride (PP-g-MA) and nanoclay were prepared by melt proccessing in Brabender extruder. XRD analysis shows the formation of nanostructure (intercalated and exfoliated) of nanocomposite with interlayer space (d-space) increasing from $26.3 \AA$ to $30.9 \AA$. These structures, however, do not affect the microcrystalline structure of polymer part of nanocomposite in whole. The study on nonisothermal crystallization shows the development in 3-dimentional direction of crystallites, that means spherulite form of crystalline structure.
\end{abstract}

\section{INTRODUCTION}

Polymer nanoclay composites (PNC) are a new class of materials that attracts great attention due to their excellent mechanical, thermal properties as well as reduced gas and liquid permeability $[1,2]$. Among them the thermoplastic PNC (polyolefins, polyamides, polystyrene et al.) have been studied most intensively.

Polypropylene (PP) as a very popular thermoplastic resin is involved in PNC preparation due to its very good mechanical properties in combination with low price. However, pure PP hardly forms nanocomposite with nanoclay because of its nonpolarity. So, for nanocomposite preparation, PP is often modified by polar groups such as hydroxyl, maleic anhydride, etc. [3, 4]. From these modified PP, the most popular is PP grafted maleic anhydride (PP-g-MA).

It is well known that PP properties depend on its crystalline structure. Subsequently, the properties of PP/nanoclay composite should also depend on PP crystalline structure. However, using PP-g-MA instead of PP inevitably lead to some changes in crystallization behavior of nanocomposite. For that reason, there are the works devoted to crystallization behavior of nanocomposites based on PP-g-MA and nanoclay and their properties as well [5 - 9].

In this paper, the formation of nanostructure of PP-g-MA/nanoclay composite and its nonisothermal crystallization have been studied.

\section{EXPERIMENTAL}

\subsection{Materials}

In this study, PP-g-MA is prepared in our laboratory according to [10] by melt grafting. The

${ }^{*}$ Corresponding author e-mail: polymercentre@mail.hut.edu.vn 
grafted MA content is $0.5 \%$ (by weight). Nanoclay is I28E derived from Nanocor Company (USA).

PP-g-MA/nanoclay composite was prepared by direct melt mixing in Brabender mixer (Germany) with the speed $120 \mathrm{rpm}$ and temperature $165^{\circ} \mathrm{C}$. Clay loading is $6 \%$ (by weight).

\subsection{Experimental methods}

Structure of nanocomposite is characterised by XRD method. X-ray diffraction is performed by Bruker D5005 diffractometer operated at $40 \mathrm{kV}$ and $30 \mathrm{~mA}$. Scaning rate is $2 \% \mathrm{~min}$. from 0.6 to $40^{\circ}$.

Crystallisation is studied using differential scanning calorimetry (DSC) on Bahr DSC 310 calorimeter (Germany) according to ISO 11357-1: 1997 (E). The temperature is correlated with indium. For elimination of thermal history, the samples were melted at $200^{\circ} \mathrm{C}$ for $10 \mathrm{~min}$. and then cooled at constant cooling rates of 2.5 and $10 \mathrm{~K} / \mathrm{min}$.

\section{RESULTS AND DISCUSSION}

\subsection{Formation of nanostructure}

When PP-g-MA was mixed with nanoclay at high temperature and appropriate shear rate, its molecules would intercalate into silicate layers and expand the interlayer space. The formation of these structures should be expressed on XRD pattern of PP-g-MA/nanoclay composite (Fig. 1).

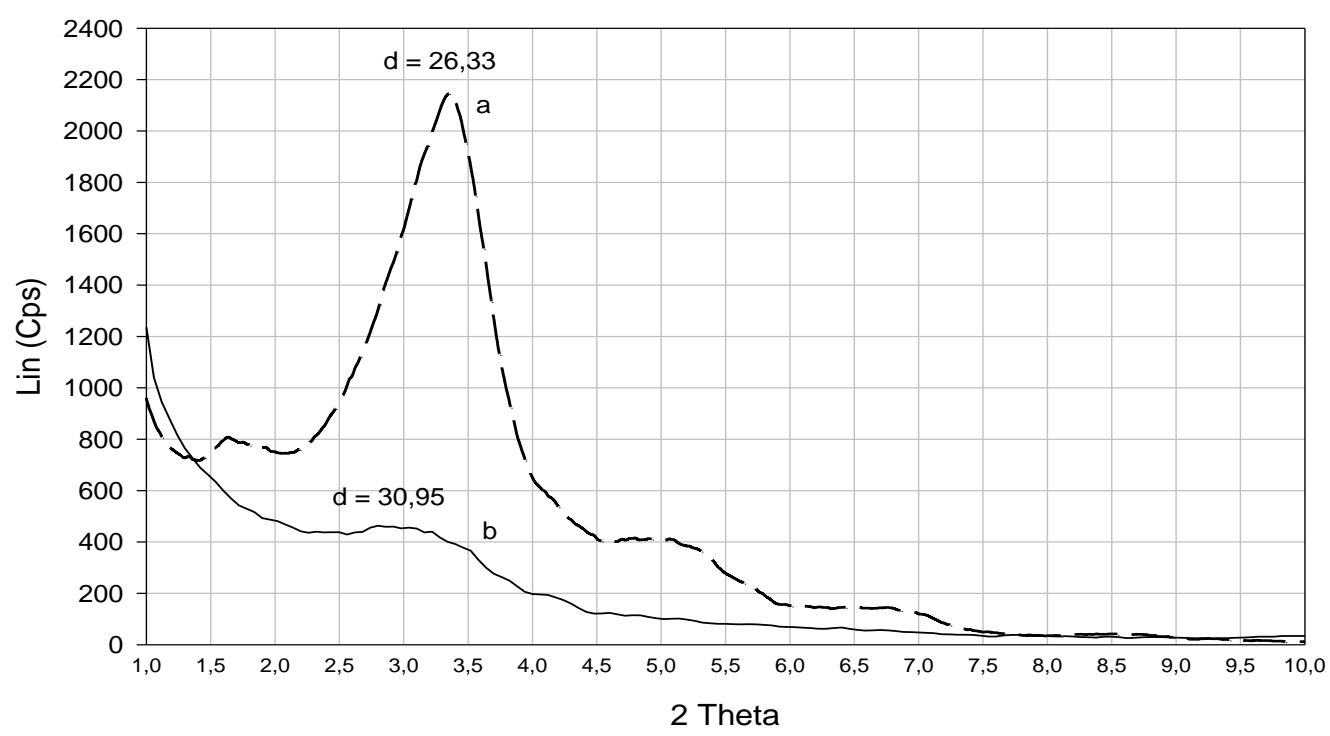

Fig. 1: XRD pattern for (a) nanoclay I28E, (b) PP-g-MA/ nanoclay composite.

From X-ray diffration data, one can see that the interlayer space $d$ extend remarkably: from $26.3 \AA$ for $\mathrm{I} 28 \mathrm{E}$ to $30.95 \AA$ for nanocomposite. That means polymer molecules were able to move into silicate layers and form intercalated structure.

Based on XRD data, some parameters of nanocomposite may be calculated, using Scherer 130 
formula [11]

$$
t=\frac{0.95 \lambda}{B \cdot \cos \theta}
$$

where $\quad t-$ the crystallite thickeness

$\lambda$ - X-ray wave length

$\theta$ - Bragg angle

B - nominated peak width, defined as $B^{2}=B_{s}^{2}-B_{s t}^{2} ; \mathrm{B}_{\mathrm{s}}, \mathrm{B}_{\mathrm{st}}$ are peak width of sample and standard material respectively.

The average number of silicate layer (n) may be calculated roughly as:

$$
n=\frac{t}{d}
$$

where $\mathrm{d}$ - interlayer space of nanoclay.

Calculated parameters are presented in Table 1.

Table 1: Characteristic parameter of nanoclay and nanocomposite (PPNC).

\begin{tabular}{lll}
\hline Item & I28E & PPNC \\
\hline Interlayer space, $\AA$ & 26.33 & 30.95 \\
Crystallite thickness, $\AA$ & 313 & 80 \\
Number of silicate layer & 12 & 2.5 \\
\hline
\end{tabular}

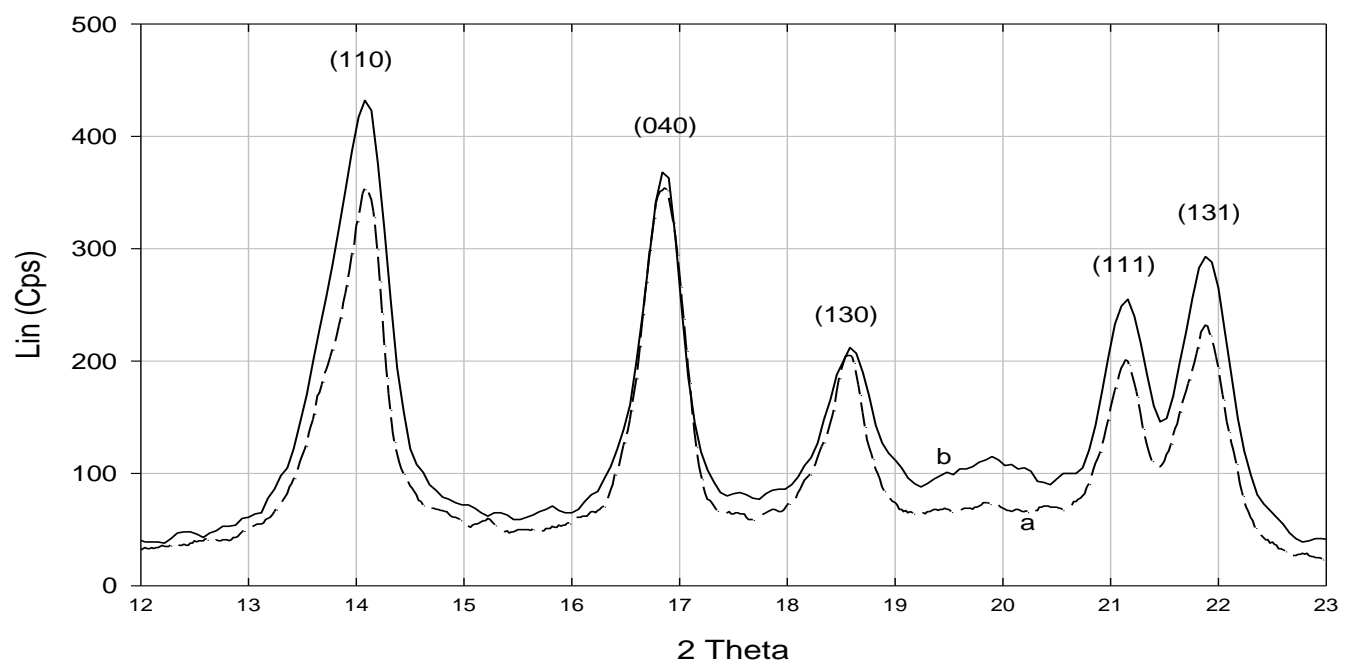

Fig. 2: XRD pattern at wide angle for (a) PP-g-MA, (b) PP-g-MA/nanoclay composite.

Calculated values of crystallite thickness and average number of silicate layers, as shown in Table 1, indicate that beside intercalated structure, in nanocomposite exist even exfoliated 
structures. The crytallite thickness reduces from $313 \AA$ (for I28E) to $80 \AA$ (for nanocomposite), and average number of silicate layers decreases from 12 to 2.5 respectively, that means a part of nanoclay splits off from crystallite edges.

The existence of exfoliated structure may be seen also on XRD parttern (Fig. 1): charateristic peak for nanocomposite at small angle $2 \theta$ is obviously more obtuse than that of I28E.

For more detail assess to microstructure of PPNC, the comparision of XRD patterns at wide angles for PP-g-MA and PP-g-MA/nanoclay composite was made (Fig. 2).

From Fig. 2 one can see these patterns almost coincide to each other at wide angle. That mean there is no change in microstructure (crystalline) of nanocomposite. The formation of intercalated and exfoliated structures of nanoclay does not affect to microcrystalline structure on the whole.

In general, the XRD analysis of PP-g-MA/nanoclay composite shows the formation of nanostructures (exfoliated and intercalated). Beside, it also indicates the structure of polymer part outside of nanocrystallites is similar to that of virgin polymer.

\subsection{Crystallization behavior of PP-g-MA/nanoclay composite}

The crystallization behavior of PP-g-MA/nanoclay composite was studied by using differential scanning calorimetry (DSC). The DSC curve of PP-g-MA/nanoclay composite at cooling rate 10 $\mathrm{K} / \mathrm{min}$ was presented in Fig. 3. For comparision, the DSC curve of PP-g-MA was presented, too.

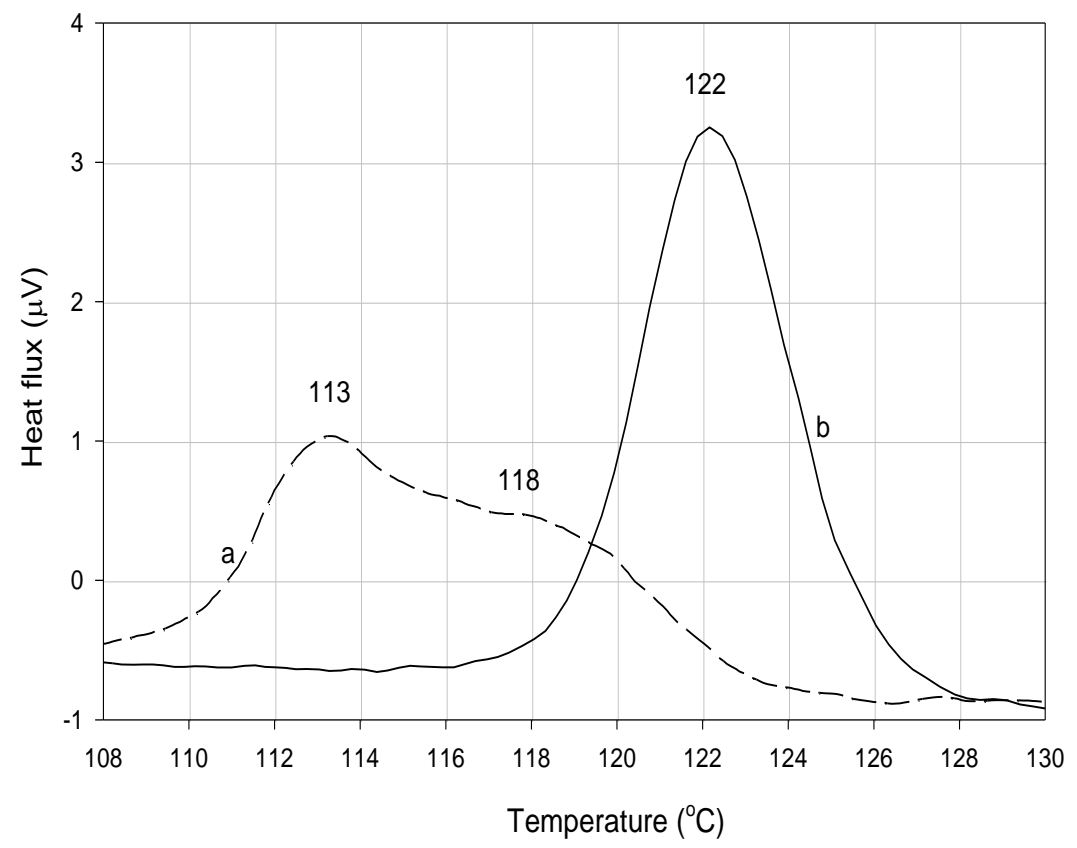

Fig. 3: DSC exotherms of (a) PP-g-MA, (b) PP-g-MA/nanoclay composite (cooling rate 10 $\mathrm{K} / \mathrm{min}$ ).

From exotherms on Fig. 3 obviously that PP-g-MA/nanoclay composite crytallised at temperature higher $\left(122^{\circ} \mathrm{C}\right)$ than PP-g-MA $\left(113^{\circ} \mathrm{C}\right)$. Besides, the exotherm of nanocomposite shows only one peak with smaller width, while PP-g-MA exotherm shows two obtuse peak. It 
indicates that crystallization of PP-g-MA/nanoclay composite occurs in one stage at higher rate than PP-g-MA, where crystallization has two stages. The reason of this may be the nucleation effect of nanoclay, that points out in literature $[5,12,13]$.

For more detail study on nonisothermal crystallization of PP-g-MA/nanoclay composite, the Avrami equation is used. Although this equation is well known for isothermal crystallization, it can be successfully applied for nonisothermal crystallization of nanocomposite $[5,13]$.

$$
1-X_{t}=\exp \cdot\left(-Z . t^{n}\right)
$$

where $X_{t}$ - relative crystallizion degree at moment $\mathrm{t}$ and defined as:

$$
X_{t}=\frac{\int_{T_{0}}^{T}\left(d H_{c} / d T\right) d T}{\int_{T_{0}}^{T_{e}}\left(d H_{c} / d T\right) d T}
$$

$\mathrm{T}_{0}, \mathrm{~T}_{\mathrm{e}}$ - the temperatures at beginning and end of crystallization process $\mathrm{dH}_{\mathrm{c}} / \mathrm{dT}$ - heat flow at temperature $\mathrm{T}$

Avrami equation (1) can be converted as:

$$
\log \left[-\ln \left(1-X_{t}\right)\right]=\log Z_{t}+n \log t
$$

where $\quad \mathrm{n}$ - isothermal Avrami exponent

$\mathrm{Z}$ - crystallisation kinetic rate constant

Dependence of $\log \left[-\ln \left(1-X_{t}\right)\right]$ on logt is presented on Fig. 4.

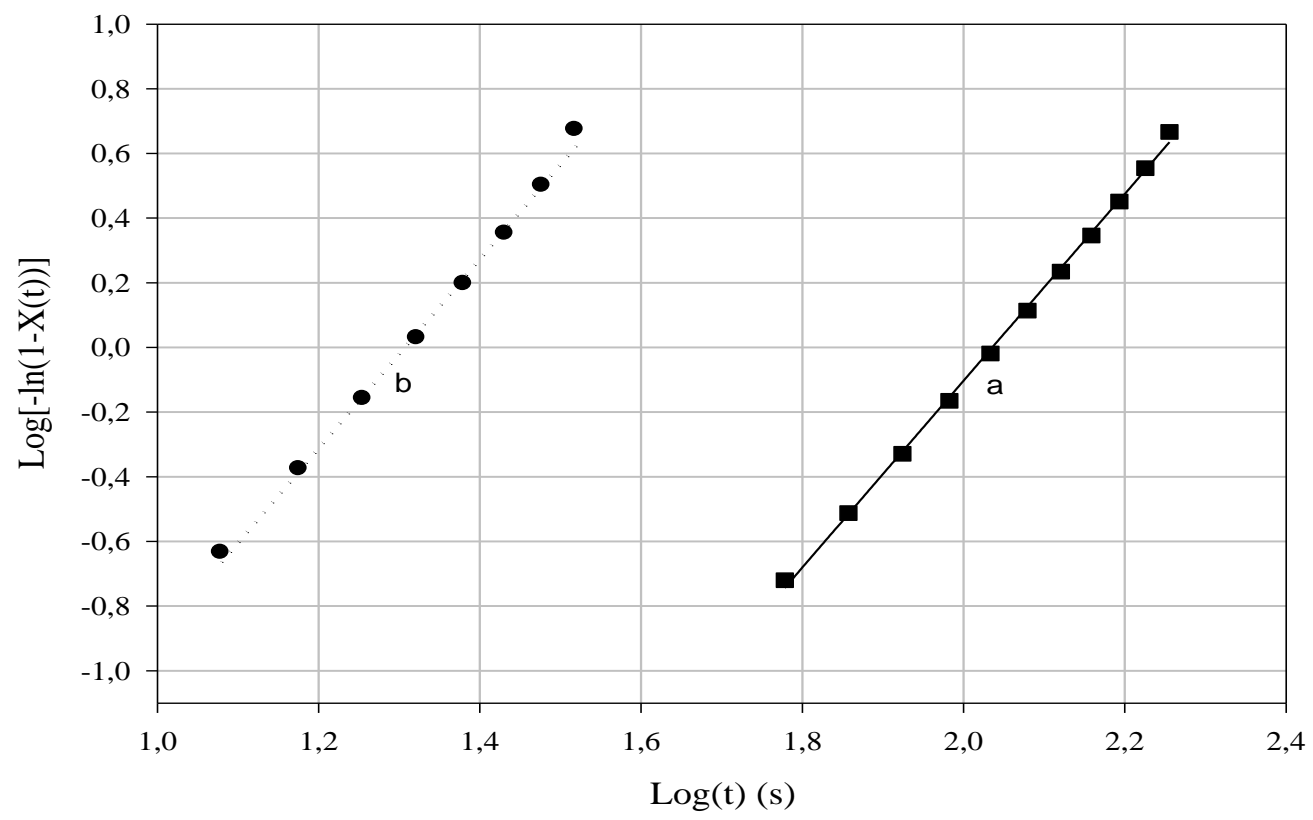

Fig. 4: Plot of $\log \left[-\ln \left(1-X_{t}\right)\right]$ versus logt at cooling rate $2.5 \mathrm{~K} / \mathrm{min}(a)$ and $10 \mathrm{~K} / \mathrm{min}(\mathrm{b})$. 
From date presented on Fig. 4 and equation (2) the crystallisation parameters were calculated (Table 2).

Table 2: Parameters $Z_{t}$ and $n$ for crystallisation of PP-g-MA/nanoclay composite.

\begin{tabular}{lll}
\hline Cooling rate & $\mathbf{Z}_{\mathbf{t}}$ & $\mathbf{n}$ \\
\hline $2.5 \mathrm{~K} / \mathrm{min}$ & $1.31 .10^{-6}$ & 2.889 \\
$10 \mathrm{~K} / \mathrm{min}$ & $1.51 .10^{-4}$ & 2.927 \\
\hline
\end{tabular}

As clearly shown in Table 2, in both case the value of Avrami paramenter $n$ is around 3. Due to nucleation effect of nanoclay, it may be considered that crystalline nuclei are formed immediately at the beginning of process, so crystalline structures of nanocomposite developed in 3-dimentional directions independently on cooling rate. It quite agreed with the authors [12 14] who point out the spherulite structures of polypropylene-clay nanocomposite. The difference in values of paramater $\mathrm{Z}$ shows only various crystallisation degrees.

\section{CONCLUSIONS}

1. In formation of PP-g-MA/nanoclay composite, the intercalated and exfoliated structures were formed. However, in the polymer part outside of nanostructure, the crystalline character remains unchanged.

2. PP-g-MA/nanoclay composite crystallise at higher temperature with higher rate in comparison with neat PP-g-MA. Analysis of nonisothermal crystallisation show that crystalline structures of nanocomposite develop in 3-dimentional directions (in form of spherulites) independently on the crystallisation rate. It is due to nucleation effect of nanoclay in polymer matrix.

\section{REFERENCES}

1. Alexandre, M. and Dubois, P. (2000), Polymer layered Silicate Nanocomposites: Preparation, Properties and Use of a New Class of Material, Mater. Sci. and Eng., T.2B, pp. $1-63$.

2. Pinnavaia, T.J. and Beall, G.W. (2000), Polymer - Clay Nanocomposites, John Wiley \& Sons Ltd., Chichester-New York, Weinhem-Brisbane, Singapore-Toronto, p. 349.

3. Sangeeta Hambirn, Neelima Bulakh, and Jog, J.P. (2002), Polypropylene/Clay Nanocomposites: Effect of Compatibilizer on Thermal, Crystallization and Dynamic Mechanical Behavior, Polym. Eng. and Sci., Vol. 42, No. 9, pp. 1800-1807.

4. Makoto Kato, Arimitsu Usuki, and Akane Okada (1997), Synthesis of Polypropylene Oligomer-Clay Intercalation Compound, J. Appl. Polym. Sci., Vol. 66, pp. 1781-1785.

5. Jian Li, Chixing Zhou, and Wang Gang (2003), Study on Nonisothermal Crystallization of Maleic Anhydride grafted Polypropylene/Montmorillonite Nanocomposite, Polymer Testing, T. 22, pp. 217-223.

6. Hasegawa, N., Kawasumi, M., Kato, M., Usuki, A., and Okada, A. (1998), Preparation and Mechanical Properties of Polypropylene-Clay Hybrid, using Maleic Anhydride modified 
Polypropylene Oligomer, J. Appl. Polym. Sci., Vol. 47, pp. 87-92.

7. Xu, W., Liang, G., Zhai, H., and Pan, W.P. (2003), Preparation and Crystallization Behavior of PP/PP-g-MAH/Org-MMT Nanocomposite, European Polym. J., T.39, pp. 1467-1474.

8. Hasegawa, N. and Usuki, A. (2004), Silicate Layer Exfoliation in Polyolephin/Clay Nanocomposites based on Maleic Anhydride Modified Polyolephins an Organophilic Clay, J. Appl. Polym. Sci., Vol. 93, pp. 464-470.

9. Manias, E., Touny, A., Wu, L., Strawhecker, K., Lu, B., and Chung, T.C. (2001), Polypropylene/Montmorillonite nanocomposites. Review of Synthesis Routes and Material properties, Chem. Mater., T. 13, pp. 3156-3523.

10. Bui Chuong and Tran Hai Ninh (2004), The Synthesis of Polypropylene graft Maleic Anhydride by Melting Method in the Brabender single screw extruder, J. of Chemistry, T. 42, No. 3, pp. 358-361 (Vietnamese).

11. Masao Kakudo and Nobutami Kasai (1972), X-ray Diffraction by Polymers, Kodansa Ltd. \& Elsevier, Amsterdam - New York - London.

12. Paralay Maiti, Pham Hoai Nam, Masami Okamoto, Tadao Kotaka, Naoki Hasegawa, and Arimitsu Usuki (2002), The Effect of Crystallization on the Structure and Morphology of Polypropylen/Clay Nanocomposites, Polym. Eng. Sci., Vol. 42, No. 9, pp. 1864-1871.

13. Jisheng Ma, Shimin Zhang, Zongneng Qi, Ge Li, and Youliang Hu (2002), Crystallization Behavior of Polypropylene/Montmorillonite Nanocomposites, J. Appl. Polym. Sci., Vol. 83, pp. 1978-1985.

14. Petr Svoboda, Changchun Zeng, Hua Wang, L. James Lee, and David L. Tomasko (2002), Morphology and Mechanical Properties of Polypropylene/Organoclay Nanocomposites, J. Appl. Polym. Sci., Vol. 85, pp. 1562-1570. 